УДК $81 ’ 255.2$

\title{
А.В. Уржса
}

\section{ЭПИСТЕМИЧЕСКИЕ ЭГОЦЕНТРИКИ: КЛАССИФИКАЦИЯ, ПРАГМАТИКА, ФУНКЦИОНИРОВАНИЕ (НА МАТЕРИАЛЕ ОРИГИНАЛЬНЫХ И ПЕРЕВОДНЫХ РУССКОЯЗЫЧНЫХ НАРРАТИВОВ)}

В статье представлена характеристика специфической группы эгоцентриков, семантика которых сопряжена со знанием или не-знанием информации, а также переходом от незнания к знанию. Указывая на ограничение точки зрения модусного субъекта текста (повествователя или фокального персонажа), такие средства усиливают интригу повествования, формируют саспенс. Выделенная группа получает название эпистемических эгоцентриков (наряду с дейктическими, оценочными и т.п.) и включает показатели персуазивности и эвиденциальности, средства выражения неопределенности и неожиданности, конструкции, постулирующие сходство и подобие, а также идентификацию. Анализ оригинальных и переводных текстов на русском языке позволяет увидеть тесное взаимодействие разных типов эпистемических эгоцентриков, активно участвующих в конструировании перспективы текста. Основной материал исследования составили варианты русского перевода романов «Дракула» Б. Стокера и «Приключения Тома Сойера» М. Твена. Сопоставление версий перевода позволяет увидеть эффект повышения драматизации и усиления субъективизации при активном использовании эпистемических эгоцентриков в рамках определенных переводческих стратегий, акцентирующих приемы авторов оригиналов.

Ключевые слова: эгоцентрики, эпистемическая семантика, неопределенность, неожиданность, субъективизация, перевод.

DOI: $10.35634 / 2412-9534-2020-30-5-765-773$

\section{Введение}

Термин «эгоцентрический» в применении к феноменам языка за последние сто лет значительно расширил свое значение. Изначально ориентированный на дейктические слова (Б. Расселл, К. Бюлер), он постепенно охватил все средства выражения субъективности в языке. Согласно определению Е.В. Падучевой, к эгоцентрикам относятся «слова, грамматические категории, синтаксические конструкции, семантика которых подразумевает, в качестве одного из участников описываемой ситуации, говорящего» [6. С. 17]. Однако термин «говорящий» здесь условен: речь идет не только о канонической ситуации устного общения, но и о любом речевом способе проявления субъекта сознания, носителя точки зрения, будь то записка или сложный нарратив. Именно эгоцентрики, таким образом, вербализуют проявления в тексте всех субъектов модуса: говорящего, адресата, а также третьих лиц, чья точка зрения в тексте представлена. Эгоцентрики разнообразны и разнородны, а потому необходимость их классификации была осознана давно. Ещё до популяризации данного термина работы о субъективности (Э. Бенвенист), модусе (Ш. Балли), модальности (В.В. Виноградов) и т.п. предложили значительное количество ценных таксономий. С опорой на эти труды современные ученые разработали различные реестры эгоцентриков (Е.В. Падучева, Н.К. Онипенко), однако эти наборы отвечают определенным исследовательским задачам и достаточно сильно различаются. Кроме того, существующие классификации детальны, но атомарны - задача ориентировать таксономию на изучение взаимодействия эгоцентриков пока не ставилась.

Исследование, результаты которого представлены в статье, включает ряд групп языковых средств, семантика которых предполагает не только особые сходства внутри общего реестра эгоцентриков, но и специфическое взаимодействие в нарративе, позволяющее объединить эти группы в единый кластер. Цель статьи - представить этот кластер, обосновать его название, охарактеризовать входящие в него группы эгоцентриков и выявить общие для них прагматические свойства, а также описать функционирование соответствующих языковых средств в нарративах. Материалом исследования стали как оригинальные тексты на русском языке, так и варианты русского перевода англоязычных текстов, демонстрирующие взаимодействие разных групп эгоцентриков при воссоздании соответствующих смыслов оригинала. 


\section{Актуальные проблемы классификации эгоцентриков}

Составление реестра эгоцентрических средств русского языка было предпринято Е.В. Падучевой, результаты этой комплексной работы нашли отражение в монографиях 1996 и 2019 гг. (а также в целом ряде статей). В этих трудах Е.В. Падучева представляет наборы эгоцентриков по-разному, и для нас важно направление этих изменений. Кратко сопоставим раннее и позднее представление о реестре эгоцентриков в работах этого ученого.

В монографии Е.В. Падучевой «Семантические исследования» (1996) глава раздела «Семантика нарратива», посвященная эгоцентрическим средствам, включает следующие группы слов с «эгоцентрическим участником» (перечислим их в порядке, выбранном автором [5. С. 261-284]): дейктические слова (я, здесь, сейчас), вводные слова (кажется), слабоопределенные местоимения (одна <noлячка>), презумпции, входящие в семантику слова (он пенсионер, но любит музыку), релятивные номинации (сестра $<$ пришла $>$ ), оценочные слова, метатекстовые элементы (во-первых, итак), предикаты внутреннего состояния (жаль, чувствовалось), предикаты со значением сходства и подобия (напоминал $<$ Гоголя>), показатели идентификации (mom caмый), слова со значением неожиданности (вдруг, внезапно, неожиданно), неопределенные местоимения и наречия (что-то, где-то, ) и соответствующие номинации (незнакомый), обобщающие «врезки» (как часто бывает).

Приведенный список не оформлен как классификация, это и не планировалось автором, судя по тому, что одна часть реестра представлена в параграфе «Эгоцентрические элементы языка. Примеры», а другая часть - в параграфе «Прочие типы эгоцентрических элементов». Объектом изучения в данной работе стали все эгоцентрики в целом, их общие свойства, проявляемые в речи и в нарративах разных типов.

В монографии «Эгоцентрические элементы языка» (2019) была предпринята попытка упорядочить набор эгоцентриков. Е.В. Падучева выделила пять «семантических сфер эгоцентрии»: дейксис, модальность, оценку, эвиденциальность и коммуникативную структуру (тема-рематическое членение предложения), «которая имеет дело с оппозицией известное / неизвестное (для адресата)» [6. С. 81]. Предложенное семантическое деление (за исключением последней сферы) отчасти сближается с классификацией модусных смыслов Т.В. Шмелевой [9], однако оно предстает более общим. При этом распределение языковых средств по отмеченным сферам эгоцентрии не произведено - их детальная классификация пока не построена. В частности, неясно, к какой сфере нужно отнести неопределенные местоимения и наречия или показатели идентификации: они традиционно не включаются в зоны дейксиса, оценки, модальности, коммуникативной структуры, хотя могут иметь отношение к их реализации. Эвиденциальность, которая «выражает источник сведений говорящего о ситуации или, точнее, путь доступа к сообщаемой информации» [6. С. 90] также традиционно связывается в русском языке с другими средствами (якобы, будто бы и т.п., а также мол, де, дескать и др.). Получается, что ни одна из пяти выделенных сфер не включает соответствующую группу элементов.

Не определяется однозначно и статус предложений с неопределенно-личным субъектом (они не упомянуты в реестре, но включены в качестве объекта описания в один из параграфов книги). В ряде контекстов такие предложения актуализируют определенный тип эвиденциальности, указывая на способ получения информации (За стеной пели), поддерживают семантику невысокой степени уверенности (Туда, кажется, вошли), а в других ситуациях реализуют оценочные и дейктические смыслы, подчеркивая отчуждение деятеля от говорящего, а нередко и от адресата (Говорят - а ты не слушай, говорят - а mы не верь). Таким образом, описанный Е.В. Падучевой объемный реестр средств эгоцентрии, а также предложенные ей основы его классификации стимулируют поиск дальнейших, конкретизирующих решений в этой области.

Если в приведенных выше трудах об эгоцентрии в фокусе оказываются лексические единицы и некоторые грамматические категории языка, то в работах Н.К. Онипенко и Е.Н. Никитиной акцент смещается на явления синтаксиса - это в первую очередь так называемые эгоцентрические нули (незамещенные позиции субъекта в предложении, интерпретируемые в связи с определенным носителем точки зрения) и эгоцентрическая техника, то есть использование таких «значимых отсутствий» при конструировании перспективы текста. Изучаются предложения, «которые без местоимения Я и аффиксов 1-го лица осмысливаются в связи с Я-модусной рамкой», то есть эгоцентрики трактуются более узко [3. С. 111]. Различаются эгоцентрические нули с дейктическим (определенно-личным) и кванторным (неопределенно-личным, неопределенно-предметным и обобщенно-личным) значением. Выбранный учеными подход позволяет исследовать нюансы функционирования конструкцийэгоцентриков, сопоставление же их с другими средствами выражения субъективности проводится на уровне конкретных текстов - специальная объединяющая таксономия для этого не разрабатывается. 
Эпистемические эгоцентрики: классификация, прагматика, функционирование...

Поскольку целью нашего исследования является изучение взаимодействия эгоцентриков разных типов в текстах на русском языке, выработка классификации таких элементов для нас необходима [7]: некоторые типы показателей субъективности проявляют больше семантических и прагматических сходств, чем другие, и могут быть объединены в соответствующие кластеры.

\section{Состав кластера эпистемических эгоцентриков: семантическая и прагматическая специфика}

В центре нашего внимания оказывается кластер, группирующий средства, сопряженные со знанием или не-знанием информации, а также переходом от незнания к знанию, опознанию, узнаванию. Общей семантической базой для объединения разнообразных эгоцентриков в этой сфере становится ограничение точки зрения любого модусного субъекта текста и оппозиция "неполнота информации" - "полнота информации", где ключевой параметр полноты определяется субъективно - по отношению к предшествующей и последующей частям текста (с опорой на них может происходить верификация или уточнение информации). Именно в соответствии с базовой семантикой объединяемых средств кластер может получить название эпистемических эгоцентриков. Общий прагматический эффект использования средств этой группы заключается в приобщении адресата (читателя) к границам точки зрения фокального субъекта. Языковые средства, очерчивающие степень и характер осведомленности фокальных персонажей и повествователя о происходящих событиях, взаимодействуют, формируя интригу, влияя на читательские ожидания.

В кластер эпистемических эгоцентриков могут быть включены:

- средства выражения персуазивных смыслов (вероятно, может быть, кажется, наверняка и т. п.);

- показатели неопределенности: неопределенные и слабоопределенные местоимения (кто-то, некоторые), неопределенные наречия (когда-нибудь), слова, указывающие на недостаточную информированность (неизвестный, незнакомеи), предложения с неопределенно-личным (K нам постучали) и неопределенно-предметным субъектом (В репродукторе щелкнуло);

- показатели идентификации (тот же, тот самый, не кто иной как), глаголы и сочетания, указывающие на идентификацию (узнать, опознать, признать, оказаться кем-то);

- слова со значением неожиданности (вдруг, внезапно, неожиданно);

- обороты, постулирующие сходство: конструкции с союзами как, будто, словно, точно, подобно и т.п., предикаты напоминал, был похож;

- показатели эвиденциальности (говорят, считали, мол, дескать, явно и т.п.);

- «обобщающие врезки» (как это часто бывает, как нередко случается и т.п.).

На близость некоторых из перечисленных групп неоднократно указывали исследователи. Так, Н.Д. Арутюнова в статье «Тождество и подобие (заметки о взаимодействии концептов)» пишет: «Тождество устанавливается в акте идентификации, сходство - в акте уподобления. Оба эти акта предполагают сравнение» [1. С. 8]. Е.В. Падучева отмечает: «Существует тесная связь между эвиденциальностью и эпистемической модальностью: эпистемическая модальность обычно означает выраженную говорящим неполную степень достоверности сообщаемой им информации, а эвиденциальность маркирует источники информации, на которых говорящий основывает свое высказывание - тем самым частично снимая с себя ответственность за достоверность информации» [6. С. 91]. Слова со значением неожиданности характеризуют то, о чем человек не знал заранее, но и идентификация объекта в ряде случаев может быть определена как «замена неизвестного (субъекту) на известное» [5. С. 281]. Неслучайно оба смысла объединяются в сочетании оказаться + имя с идентифицирующей или признаковой семантикой (Незнакомеи оказался нашим дворником. Наш дворник оказался кандидатом наук). Использование неопределенных местоимений, так же как и показателей низкой степени уверенности, зачастую связано с недостаточной информированностью, а введение слабоопределенных местоимений - с дефокусированием, аналогичные значения выделяются и у предложений с неопределенно-личным субъектом [8]. Использование обобщений или показателей эвиденциальности - это попытка соотнести свою точку зрения с иной, противопоставить их или присоединиться к чужому мнению. Интересно, что использование сравнений - это тоже отчасти апелляция к иной, расширенной точке зрения (мы сравниваем объект с тем, что было ранее доступно нашему восприятию или пониманию и что знакомо также потенциальному адресату).

Итак, подгруппы эпистемических эгоцентриков демонстрируют немало смысловых и функциональных сближений, и в нарративе они нередко оказываются рядом. Поскольку всю информацию о со- 
бытиях, описанных в тексте, читатель получает опосредованно, его точка зрения вынуждено ограничена. Приобщаясь к знанию, которым обладают текстовые субъекты, он может верифицировать эту информацию только с опорой на представленные точки зрения. Если эпистемические эгоцентрики в определенном фрагменте текста аккумулируются - в нём создается атмосфера напряжения, догадки, саспенса.

В повествовании эпистемические эгоцентрики могут функционировать как аукториальные или персонажные. Первые открывают для читателя доступ к позиции повествователя - его знанию, сомнениям, гипотезам, обобщениям, отсылкам. Нередко именно таким образом в тексте создается образ нарратора как живого собеседника, которому не чужда ограниченность знания (порой иронически подчеркнутая или использованная в игровых целях). Эгоцентрики второго типа (персонажные) в перволичном повествовании конструируют образ говорящего, а в третьеличном - приобретают иную функцию: они способствуют субъективизации нарратива, то есть приближению позиции повествователя к точке зрения того или иного персонажа, распространению внутренней фокализации [10]. В подобных контекстах аккумуляция и взаимодействие эпистемических эгоцентриков несут особую художественную нагрузку.

Яркие примеры субъективизации повествования мы находим у А.П. Чехова: некоторые его рассказы, написанные от третьего лица, практически полностью представляют точку зрения героя. Эпистемические эгоцентрики, наполняющие такие тексты, «поддерживают» друг друга, позволяя читателю надолго погрузиться во внутренний мир фокального персонажа:

Преосвященный Петр устал. Дьхание у него было тяжелое, частое, сухое, плечи болели от усталости, ноги дрожали. И неприятно волновало, что на хорах изредка вскрикивал юродивый. $А$ тут ещзе вдруг, точно во сне или в бреду, показалось преосвященному, будто в толпе подошла к нему его родная мать Мария Тимофеевна, которой он не видел уже девять лет, или старуха, похожая на мать, и, принявши от него вербу, отошла и всё время глядела на него весело, с доброй, радостной ульгкой, пока не смешалась с толпой. И почему-то слезы потекли у него по лииу. На душе было покойно, всё было благополучно, но он неподвижно глядел на левый клирос, где читали, где в вечерней мгле уже нельзя было узнать ни одного человека, и - плакал. < .. > Вот вблизи еще кто-то заплакал, потом дальще кто-то другой, потом ещуе и ещзе, и мало-помалу церковь наполнилась тихим плачем.

Жирным шрифтом в приведенном фрагменте рассказа «Архиерей» выделены эпистемические эгоцентрики разных типов. Именно они позволяют сформировать и передать читателю сложные, не поддающиеся однозначной трактовке ощущения больного героя, находящегося в пограничном состоянии между сном и явью, пораженного впечатлениями и не доверяющего им, расслабленного и в то же время обеспокоенного, выделяющего в окружающем мире очень конкретные образы, детали, шумы. Читатель погружается в противоречивое состояние героя, обретая смутное ощущение тревоги от зыбкости окружающего его мира, не зная еще, что Петр находится на пороге смерти.

Эпистемические эгоцентрики - колоритная палитра для формирования психологического повествования, и объемный набор средств русского языка позволяет реализовать приемы, использованные разными авторами, не только в оригинальных текстах, но и в вариантах перевода иноязычных произведений. Сопоставление вариантов русского перевода позволяет нам увидеть взаимодействие эпистемических эгоцентриков в ходе преобразования текста, воссоздания смыслов подлинника, воплощения переводческих стратегий.

В качестве материала мы рассмотрим варианты перевода двух англоязычных произведений с яркой интригой, созданных мастерами приключенческого жанра. Это три перевода романа Брэма Стокера «Дракула» ${ }^{1}$, представляющего перволичное повествование, и шесть переводов романа Марка Твена «Приключения Тома Сойера»², где значительное место занимает третьеличный нарратив.

\section{Взаимодействие эпистемических эгоцентриков в оригинале и в русских версиях романа «Дракула»}

Роман Б. Стокера «Дракула», одно из первых и самых известных фантастических произведений о графе-вампире, относится к жанру так называемого «готического романа»: атмосфера таинственности и страха создается в нем намеренно при помощи разнообразных языковых средств, среди кото-

\footnotetext{
1 Это переводы Н. Сандровой (псевдоним Н.Я. Гольдберг, 1913), Т. Красавченко (1993) и Д. Лаврентюка (2012). Подробные данные обо всех русских переводах, использованных в исследовании, опубликованы на исследовательском сайте A.В. Уржи, URL: http://urzha.ru/?page_id=1649.

${ }^{2}$ Переводы С. Воскресенской (1896), М. Энгельгардта (1911), К. Чуковского (1935, ред. в 1958), Н. Дарузес (1948). С. Ильина (2011) и А. Климова (2012).
} 
Эпистемические эгоцентрики: классификация, прагматика, функционирование...

рых эпистемические эгоцентрики играют значительную роль. В тексте слова со значением неопределенности, невысокой степени уверенности и неожиданности сопровождают каждый поворот сюжета, наполняют дневниковые записи и письма персонажей, формирующие роман. В результате даже небольшие детали повествования приобретают значимость в ряду загадочных сюжетных перипетий. Приведем (с некоторыми купюрами) один из фрагментов в оригинале и в переводе Т.В. Красавченко, выделяя эпистемические эгоцентрики:

Suddenly, away on our left, I saw a faint flickering blue flame. The driver saw it at the same moment; he at once checked the horses, and $\langle\ldots>$ disappeared into the darkness. $<\ldots>$ while I wondered the driver suddenly appeared again, $<\ldots>$ and we resumed our journey. I think I must have fallen asleep and kept dreaming of the incident, for it seemed to be repeated endlessly, and now looking back, it is like a sort of awful nightmare. Once the flame appeared near the road $<\ldots>$ He went rapidly to where the blue flame arose it must have been very faint, for it did not seem to illumine the place around it at all and gathering a few stones, formed them into some device.

Вдруг слева мне привиделся слабый мериающий голубой огонек. В тот же миг заметил его и возница; он сразу остановил лошадей $u,<\ldots>$ исчез в темноте. $<\ldots>$ пока я недоумевал, мой провожатый вернулся, < ..> и мы поехали дальше. Я, должсно быть, задремал, и мне все время снился этот эпизод: он повторялся много раз. И теперь, когда я вспоминаю нашу поездку, она мне кажется чудовищным кошмаром. Как-то раз голубой огонь возник близко к дороге < ...>. Он быстро подошел к месту, где появился голубой огонь, видимо, очень слабый, потому что почти не освещал ничего вокруг, и, собрав несколько камней, что-то соорудил из них. (Перевод Т. Красавченко)

Приведенный фрагмент можно назвать практически бессобытийным - если что-то важное и происходит вокруг героя, он не в состоянии это осознать, но именно в создании этой атмосферы напряженности и непонимания и играют важную роль выделенные элементы.

Особую художественную нагрузку в тексте романа получают конструкции, переносящие акцент с деятеля на само действие (девербативы с незаполненной субъектной валентностью, предложения в пассивном залоге). Одним из ярких средств передачи не только семантики, но и прагматики таких конструкций становятся русские неопределенно-личные предложения: на первый план выходит их способность указывать на недостаточную осведомленность фокального персонажа. «Затушевывание» деятеля способствует усилению интриги. Для создания сходного эффекта могут быть использованы также неопределенные местоимения и лексика, указывающая на незнание, отсутствие информации. С этими средствами взаимодействуют союзы со значением уподобления, добавляющие ощущение приблизительности, неточности описания, например:

I tried to stir, but there was some spell upon me.

Я была не в силах пошевелиться. Какая-то неведомая сила приковала меня к месту. (Перевод Н. Сандровой)

Я пробовала встать, но не могла пошевелиться, как будто меня околдовали. (Перевод Т. Красавченко)

Я не могла пошевелиться, будто находилась под влиянием какого-то колдовства. (Перевод Д. Лаврентюка)

Каждый переводчик по-своему использует эпистемические эгоцентрики, интерпретируя наполненное загадками повествование. Неопределенно-личные предложения последовательно вводятся в переводе Т. Красавченко в тех случаях, когда герой сталкивается с новой тайной. Сравним варианты:

A key was turned with the loud grating noise of long disuse.

Ключ с большим трудом, как бы после долгого бездействия, повернулся в замке. (Пер. Н. Сандровой)

Повернулся в замочной скважине ключ-им явно давно не пользовались. (Пер. Т. Красавченко)

Mate could not make out what was wrong. They only told him there was SOMETHING, and crossed themselves.

Старший офичер не мог добиться толку, матросы только сказали, что было "что-то", и перекрестились. (Пер. Н. Сандровой)

Помощник никак не может добиться, что случилось: ему сказали только - на судне творится что-то неладное - и перекрестились. (Пер. Т. Красавченко)

В первом примере субъектная валентность при девербативе disuse не заполнена, таинственные жители замка не названы - переводчики выбирают разные варианты, преследуя одну и ту же цель подчеркнуть, что герой вынужден строить неточные гипотезы, не видя никого в замке, кроме Дракулы. Н. Сандрова использует для этого сочетание как бы, Т. Красавченко - показатель эвиденциально- 
сти явно и неопределенно-личное предложение. Во втором фрагменте оригинала ключевым становится слово something, выделенное графически и указывающее на загадочное явление (которое позже станет причиной гибели всей команды). Обе переводчицы использовали неопределенное местоимение, однако в варианте Т. Красавченко мистическая окраска события усилена синтаксическими средствами: хотя речь идет о наблюдаемом действии группы людей, находящихся на судне, неопределенно-личное предложение делает информацию о субъекте более расплывчатой, перенося внимание читателя на загадочные слухи и суеверный жест. В целом количество неопределенно-личных конструкций в версии Т. Красавченко в три раза превышает их количество в варианте Н. Сандровой ${ }^{1}$.

Показатели неожиданности, неуверенности и неопределенности нередко выступают в оригинале романа в единой функциональной связке, и переводчики сами выбирают, в какой комбинации представить эти смыслы при помощи средств русского языка:

His eyes suddenly seemed to catch something in one of them, "The Westminster Gazette", I knew it by the color, and he grew quite white.

Я заметил, что какая-то заметка в "Курьере" поразила его. (Пер. Н. Сандровой)

Воруг что-то привлекло его в газете. Он побледнел ... (Пер. Т. Красавченко)

Вдруг глаза его остановились на какой-то статье. Он побледнел, внимательно перечитал статью... (Пер. Д. Лаврентюка)

Подсчеты показывают, что Т. Красавченко чаще использует показатели невысокой степени уверенности, чем остальные переводчики (например, слова казалось и кажется встречаются в этом переводе суммарно 117 раз, у Н. Сандровой 56 раз). Переводчица задействует их не только для прямой передачи соответствующих оригинальных смыслов, но и в качестве элементов своеобразной функциональной «связки», в которой один эпистемический эгоцентрик поддерживает другой:

As I listened, I heard as if from down below in the valley the howling of many wolves.

Воруг я рассльшиал далекий, протяжный вой волков. (Пер. Н. Сандровой)

Прислушавшись, я различил где-то, кажется, внизу в долине, вой волков. (Пер. Т. Красавченко)

Прислушавшись, я уловил где-то вдалеке вой волков. (Пер. Д. Лаврентюка)

Неточность, субъективность впечатлений героя в оригинале возникает в ситуации напряжения, обусловленного неведением: переводчики формируют сходное впечатление при помощи разных эпистемических эгоцентриков, которые могут сочетаться, усиливая общий эффект таинственности происходящего. Материал художественных переводов, где эквивалентность семантических преобразований не ограничена уровнем предложения, таким образом, демонстрирует нам тесное взаимодействие эпистемических эгоцентриков при интерпретации нарратива, создающего атмосферу зловещей интриги, постоянно держащего читателя в состоянии напряжения.

\section{Переводческие стратегии интерпретации эпистемических эгоцентриков в русских переводах романа «Приключения Тома Сойера»}

Вторая группа текстов, привлеченных нами в ходе исследования, представляет шесть русских переводов книги Марка Твена «Приключения Тома Сойера», следующей традиции авантюрного романа. В отличие от «Дракулы», повествование о Томе оформлено в третьем лице (за исключением диалогов) и может быть квалифицировано как субъективированный нарратив: точка зрения повествователя часто сближается с позицией того или иного фокального персонажа (Тома, Гека, Бекки, тёти Полли и др.).

Роман насыщен приключениями: одна сюжетная коллизия сменяет другую, герои сталкиваются с неожиданностями, страдают в неведении, заблуждаются и вдруг узнают истину, их осеняют новые идеи, подстерегают разочарования. Автор мастерски создает ограничения для точки зрения каждого из персонажей, подчеркивая субъективность восприятия происходящего при помощи палитры эпистемических эгоцентриков: показателей персуазивности и эвиденциальности, средств выражения неопределенности и неожиданности, конструкций, постулирующих сходство и подобие, а также идентификацию.

Сопоставление вариантов русского перевода романа относительно оригинала с применением методик семантико-синтаксического и количественного анализа позволило сделать следующие наблюдения. В тех эпизодах, где повествование субъективизируется, русские переводчики склонны конденсировать эпистемические эгоцентрики, подчеркивая внутреннюю фокализацию, приобщая чи-

\footnotetext{
${ }^{1}$ Перевод Д. Лаврентюка не оцифрован, подсчеты по нему затруднены, однако анализ показывает, что он использует наименьшее количество эпистемических эгоцентриков, сокращая текст (см., например, его вариант: Помощник никак не мог добиться от них, что случилось. Матросы постоянно крестятся).
} 
Эпистемические эгоцентрики: классификация, прагматика, функционирование...

тателя к точке зрения того или иного персонажа. Рядом с элементами, коррелирующими с исходным текстом (например, показателями невысокой степени уверенности), в качестве изофункциональных «спутников» могут появиться другие эпистемические эгоцентрики, уместные в данном контексте (например, слова со значением неопределенности).

В нижеследующем фрагменте описываются впечатления и страхи не спящего ночью Тома:

Everything was dismally still. By and by, out of the stillness, little, scarcely perceptible noises began to emphasize themselves. $<\ldots>$ Old beams began to crack mysteriously. The stairs creaked faintly. Evidently spirits were abroad.

Вокруг иарила гнетущая тишина, но постепенно из этой тишины начали выделяться какие-то незначительные, порой едва различимые звуки. <..> Старые балки на чердаке таинственно потрескивали. Поскрипывала лестница, - должно быть, по ее ступеням бродили духи. (Пер. А. Климова)

Всюду господствовала томительная тишина. <...> старыя балки покрякивали тихонько, на лғсттницг что-то скрипнуло. Ясно было, что духи разгуливаются. (Пер. С. Воскресенской)

Царила какая-то зловещая тишина. <...> Старые балки начинали таинственно покряхтывать. Ступеньки на лестнице слабо заскрипели. Очевидно, духи пустились в свои похождения. (Пер. М. Энгельгардта)

Весь приведенный фрагмент повествования окрашен эгоцентрическими смыслами: лексика с перцептивной и эмотивной семантикой соседствует с показателем персуазивности evidently, маркирующим границу перехода от слуховых впечатлений к их фантастическому объяснению. Бессобытийный в сюжетном плане эпизод наполняется динамикой благодаря насыщенному плану модуса, саспенс возникает практически «из ничего». Добавленные переводчиками показатели неопределенности (что-то, какая-то, какие-то), акцентируют субъективность восприятия происходящего, оттеняя напряжение отрывка смыслами ограниченности восприятия и неполноты знания.

Подобные вставки обусловлены не только текстовыми, но и языковыми факторами. По сравнению с артиклями лексические показатели неопределенности воспринимаются как более интенсивные [2], при этом в русском языке именно они выступают частотными маркерами субъективности, побуждая лингвистов говорить о неопределенности как семантической доминанте русской языковой картины мира [4]. С другой стороны, используя такие средства, переводчики косвенно подчеркивают авторские приемы субъективизации. Наибольшее количество лексических показателей неопределенности обнаруживается в версиях К. Чуковского, Н. Дарузес. С. Воскресенской.

Неоднократно при интерпретации фрагментов, содержащих эпистемические эгоцентрики, переводчики эксплицируют смыслы, указывающие на неожиданность происходящего для персонажа:

A noise fell upon his ear. He was all attention in an instant. The alley door closed softly. $<\ldots>$ The next moment two men brushed by him, and one seemed to have something under his arm. It must be that box!

Внезапно послышиался какой-то шум, и он сразу насторожился. Так и есть: дверь, выходившая в переулок, тихо открылась и закрылась < ...> и минутой позже мимо прошли, едва не задев его, двое мужчин, причем один из них что-то нес под мышкой. Наверняка сундук! (Пер. А. Климова)

Приведенный фрагмент повествования включает несобственно-прямую речь, это максимальное приближение к точке зрения героя, которое может позволить форма третьеличного нарратива. Описываемая ситуация сопряжена не только с тайной, но и с опасностью: Гек выслеживает вооруженных бандитов, надеясь добыть сундук с драгоценностями, он напряжен и испуган. Опираясь на контекст, переводчики добавляют в русские версии текста не только неопределенные местоимения, но и показатели вдруг, внезапно, подчеркивающие неосведомленность героя. Наиболее активно эти элементы в субъективированных фрагментах текста используют К. Чуковский, Н. Дарузес и А. Климов.

Результаты количественного анализа текстов показывают, что некоторые переводчики не только сохраняют эпистемические эгоцентрики при переводе, но и эксплицируют соответствующие смыслы, если контекст позволяет сделать это. Использование таких стратегий приводит к повышению субъективизации текста - повествование драматизируется, читатель приобщается к мыслям героев. Таким образом переводчики акцентируют приемы, использованные в оригинале романа. На фоне других выделяется перевод К. Чуковского, лидирующий по суммарному количеству эксплицитных показателей персуазивности, неожиданности, неопределенности, по использованию сравнительных конструкций и предложений идентификации. Продемонстрируем применение подобной стратегии на примере одного из фрагментов романа:

He got out his worldly wealth and examined it - bits of toys, marbles, and trash; enough to buy an exchange of work, maybe, but not half enough to buy so much as half an hour of pure freedom. So he returned 
his straitened means to his pocket, and gave up the idea of trying to buy the boys. At this dark and hopeless moment an inspiration burst upon him!

Он вынул из карманов свои сокровища и стал рассматривать их: обломки игрушек, шарики и тому подобная рухлядь; всей этой дребедени, пожалуй, достаточно, чтобы оплатить три-четыре минуты чужого труда, но, конечно, за нее не купишь и получаса свободы! Он снова убрал свое жалкое имущество в карман и отказался от мысли о подкупе. Никто из мальчишек не станет работать за такую нищенскую плату. И вдруг в эту черную минуту отчаяния на Тома снизошло вдохновение! (Пер. К. Чуковского)

Размышления Тома, по сравнению с оригиналом, дополнительно размечены несколькими эпистемическими эгоцентриками в переводе К. Чуковского: эксплицируется высокая степень уверенности героя в его выводах и внезапность озарения новой идеей. Переводчик конденсирует эгоцентрики, акцентируя субъективирующий прием.

\section{Выводы}

Исследование поведения эпистемических эгоцентриков в оригинальных и переводных русскоязычных текстах демонстрирует их функциональную близость и подтверждает правомерность выделения соответствующего кластера в рамках крупной группы элементов с субъективной семантикой. И в психологическом повествовании, и в приключенческом нарративе появление эпистемических эгоцентриков сопровождает приемы конструирования перспективы текста, подчеркивая ограниченность точки зрения модусного субъекта, усиливая напряжение и интригу. Тесное взаимодействие эпистемических эгоцентриков проявляется в русских переводных текстах, где функциональные связи таких элементов становятся особенно заметны: эгоцентрические смыслы вербализованные в соответствии с законами языка перевода, комбинируются, поддерживают друг друга в создании общего прагматического эффекта. В перволичном повествовании их экспликация подчеркивает особенности восприятия мира каждым говорящим, в третьеличном нарративе - усиливает субъективизацию, приближая читателя к точке зрения фокальных персонажей. И в том, и в другом случае повествование драматизируется. Некоторые переводчики активно используют этот эффект, акцентируя оригинальные приемы Б. Стокера и М. Твена при помощи средств русского языка.

\section{СПИСОК ЛИТЕРАТУРЫ}

1. Арутюнова Н.Д. Тождество и подобие (заметки о взаимодействии концептов) // Тождество и подобие: сравнение и идентификация. М.: Наука, 1990. С. 7-32.

2. Нуриев В.А. Исследование категории неопределенности в русском языке на материале корпусных данных // Научные ведомости Белгородского государственного университета. Гуманитарные науки. 2015. № 24. Вып. 28. C. $14-18$.

3. Онипенко Н.К. Модель субъектной перспективы и проблема классификации эгоцентрических средств // Проблемы функциональной грамматики. Принцип естественной классификации / Отв. ред. А.В. Бондарко, В.В. Казаковская. М.: Языки славянской культуры, 2013. С. 92-121.

4. Падучева Е.В. Неопределенность как семантическая доминанта русской языковой картины мира [Электронный ресурc] URL: http://lexicograph.ruslang.ru/TextPdf1/dominanta1_1996.pdf

5. Падучева Е.В. Семантические исследования. М.: Языки славянской культуры, 1996. 464 с.

6. Падучева Е.В. Эгоцентрические единицы языка. М.: Издательский Дом ЯСК, 2019. 440 с.

7. Уржа А.В. Классификация эгоцентрических средств языка сквозь призму анализа переводного нарратива. Функциональное взаимодействие эгоцентриков // Филология и человек. 2019. № 4. С. 43-58.

8. Уржа А.В. Неопределенно-личные предложения в русских переводных нарративах (конец XIX-XX вв.): модусная семантика, прагматика // Мир русского слова. 2019. № 2. С. 24-31.

9. Шмелева Т.В. Смысловая организация предложения и проблема модальности // Актуальные проблемы русского синтаксиса. Вып.1 / Под ред. К.В. Горшковой, Е.В. Клобукова. М.: МГУ, 1984. С. 78-100.

10. Genette G. Figures III. Paris: Seuil, 1972. 286 p.

Уржа Анастасия Викторовна, кандидат филологических наук, доцент кафедры русского языка

Московский государственный университет им. М.В. Ломоносова

119991, Россия, Москва, Ленинские горы, ГСП-1, МГУ им. М.В. Ломоносова

1-й корпус гуманитарных факультетов, филологический факультет

E-mail: English2@yandex.ru 


\title{
A.V. Urzha \\ EGOCENTRIC UNITS WITH EPISTEMIC MEANING: CLASSIFICATION, PRAGMATICS, FUNCTIONING (ON THE MATERIAL OF ORIGINAL AND TRANSLATED NARRATIVES IN RUSSIAN)
}

\author{
DOI: $10.35634 / 2412-9534-2020-30-5-765-773$
}

The article presents the characteristics of the specific group of egocentric words and constructions having the semantics related to knowledge or the lack of knowledge, and dealing with the shift from the latter to the former. These egocentric units with epistemic meaning are used to demonstrate the restrictions of any point of view in the text (belonging to the narrator or the focal hero), they form the suspense in the narrative. These elements are called epistemic egocentric units (compared to deictic egocentric units, evaluative units etc.). This epistemic cluster includes the persuasive and evidential markers, the words and expressions denoting uncertainty and unexpectedness, the constructions expressing similarity, likeness and identification. The analysis of original and translated texts in Russian shows the interaction of different types of epistemic egocentric units within the perspective of the narratives. The essential material for the study is constituted by several Russian translations of the novels "Dracula" (B. Stoker) and "The Adventures of Tom Sawyer" (M. Twain). The results of the comparative analysis of translated versions show that active use of epistemic egocentrics in Russian translations reinforces suspense and dramatization within some translator's strategies, highlighting the original devices.

Keywords: egocentric units, epistemic meaning, uncertainty, unexpectedness, focalization, translation.

\section{REFERENCES}

1. Arutyunova N.D. Tozhdestvo i podobie (zametki o vzaimodejstvii konceptov) [Identity and similarity (notes on the interaction of concepts)]. Tozhdestvo i podobie: sravnenie $i$ identifikaciya [Identity and similarity: comparison and identification]. Moscow, Nauka Publ., 1990, pp. 7-32. (In Russian).

2. Nuriev V.A. Issledovanie kategorii neopredelennosti v russkom yazyke na materiale korpusnykh dannykh [Corpusbased study of the category of uncertainty in the Russian language]. Nauchnye vedomosti Belgorodskogo gosudarstvennogo universiteta. Gumanitarnye nauki. [Scientific bulletin. The Humanities], 2015, no. 24. issue 28, pp. 14-18. (In Russian).

3. Onipenko N.K. Model' sub"ektnoi perspektivy i problema klassifikatsii egotsentricheskikh sredstv [The model of subject perspective and the problem of classifying the egocentric means]. Problemy funktsional'noi grammatiki. Printsip estestvennoi klassifikatsii [Issues of functional grammar. The principle of natural classification]. Bondarko A.V., Kazakovskaya V.V. (eds.), Moscow, YASK Publ., 2013, pp. 92-121. (In Russian).

4. Paducheva E.V. Neopredelennost' kak semanticheskaya dominanta russkoy yazykovoy kartiny mira [Uncertainty as the semantic dominant of Russian language model of the world], 1996. Available at: URL: http://lexicograph.ruslang.ru/TextPdf1/dominanta1_1996.pdf), accessed 22.02.2020. (In Russian).

5. Paducheva E.V. Semanticheskie issledovaniia [Semantic studies]. Moscow, YASK Publ., 1996, 464 p. (In Russian).

6. Paducheva E.V. Egotsentricheskie edinitsy yazyka [Egocentric Units in the Language]. Moscow, YASK Publ., 2019, 440 p. (In Russian).

7. Urzha A.V. Klassifikatsiya egotsentricheskikh sredstv yazyka skvoz' prizmu analiza perevodnogo narrativa. Funktsional'noe vzaimodeystvie egotsentrikov [Classification of egocentric language units based on the analysis of translated narratives. Functional interaction of egocentrics]. Filologiya i chelovek. [Philology and the Man]. 2019, no. 4, pp. 43-58. (In Russian).

8. Urzha A.V. Neopredelenno-lichnye predlozheniya $\mathrm{v}$ russkikh perevodnykh narrativakh (konets XIX-XX vv): modusnaya semantika, pragmatika [Indefinite personal constructions in Russian translated narratives (the end of XIX-XX centuries): modal semantics, pragmatics]. Mir russkogo slova. [The World of Russian Word], 2019, no. 2, pp. 24-31. (In Russian).

9. Shmeleva T.V. Smyslovaia organizatsiia predlozheniia i problema modal'nosti [Semantic organization of a sentence and the concept of modality]. In: Gorshkona K.V., Klobukov E.V., eds. Aktual'nye problemy russkogo sintaksisa [Actual issues of Russian syntax], 1984, no. 1, pp. 78-100. Moscow. (In Russian).

10. Genette G. Figures III. Paris, Seuil, 1972, 286 p. (In French).

Received 25.02.2020

Urzha A.V., Candidate of Philology, Associate Professor at Department of Russian Language

Lomonosov Moscow State University

119991, GSP 1, Lomonosov Moscow State University, ${ }^{\text {st }}$ Humanities Building, Faculty of Philology,

Leninskiye Gory, Moscow, Russia

E-mail: English2@yandex.ru 